\title{
Monitoring the Flesh Softening and the Ripening of Peach during the Last Phase of Growth On-tree
}

\author{
Catalina Pinto, Gabino Reginato, Karen Mesa, Paulina Shinya, \\ Mariana Díaz, and Rodrigo Infante ${ }^{1}$ \\ Universidad de Chile, Facultad de Ciencias Agronómicas, Departamento de \\ Producción Agrícola, Av. Santa Rosa 11315, 8820808, Santiago, Chile
}

Additional index words. peach maturation, fruit quality, flesh softening, ripening

\begin{abstract}
The aims of this study were to characterize the softening rate of the flesh and some physiological parameters of three peach cultivars during the last phase of on-tree development. During two consecutive seasons, labeled fruits were nondestructively monitored on-tree, from the stone-hardening phase up to harvest. The absorbance index of the skin $\left(I_{\mathrm{AD}}\right)$ follows a segmented, nonlinear regression. Beyond the intersection point of the two segments of the regression, the $I_{\mathrm{AD}}$ decreased linearly at a higher rate 10 to 15 day before harvest. The most dramatic change of the $I_{\mathrm{AD}}$ coincided with the "color break" of the skin. The $I_{\mathrm{AD}}$ and the flesh softening were similar in 'Andes Du-1' and 'Loadel', while there was no difference in the growth rate of 'Bowen' and 'Loadel'. 'Andes Du-1' and 'Bowen' showed the same growth rate in the upper and the lower sections of the canopy. The fruit at the upper section showed a mass of 30 to $50 \mathrm{~g}$ greater than the fruit at the lower section. In addition, no significant changes in the evolution of the soluble solids content (SSC) were observed, with the exception of 'Loadel' located in the upper section of the canopy. Differences in the length of the fruit development period are strongly influenced by the accumulated temperature after bloom. The difference in the fruit mass, SSC, $I_{\mathrm{AD}}$, and background color depend on the position of the fruit on the canopy. The use of mixed models, based on repeated sampling over time allows to accurately describing the evolution of peach ripening.
\end{abstract}

Peaches that are growing alongside one another in a canopy show quite different ripeness levels (Lewallen and Marini, 2003). Consequently, a harvest can last for a long period, as it must be executed when the various fruit reach similar ripeness (Lurie et al., 2013). In addition, the variability in the time of ripening of fruit located in different positions of the canopy affects fruit quality (Crisosto et al., 1997; Farina et al., 2005) because fruit are exposed to unequal conditions of microclimate, and thus, the biochemical reactions associated with ripening occur at different rates (Marini et al., 1991). George et al. (1996) reported a close relationship between exposure to solar radiation and peach ripeness. Marini et al. (1991) noted that low light exposure is more detrimental to peach quality during the second half of phase III, corresponding to $\approx 3$ weeks before harvest in early-maturing cultivars. 'MayGlo' nectarine shows a higher quality at the top of a tree (Caruso et al., 2001), but Forlani et al. (2002) stated that quality is similar on peach growing in the middle or in the upper sections of the canopy. Different researches state that the

\footnotetext{
Received for publication 26 May 2015. Accepted for publication 23 Oct. 2015.

This work was made possible by the funding of FONDECYT for project no. 1130198, and by the funding of CONICYT through the scholarship "Magíster Nacional 2012," awarded to CP (Programa de Magíster, Universidad de Chile).

${ }^{1}$ Corresponding author. E-mail: roroinfante@ gmail.com.
}

soluble solids content (SSC) is higher in fruit located at the top of a tree (Caruso et al., 2001; Crisosto et al., 1995, 1997) due to the positive effect of a higher level of intercepted light (Lewallen, 2000). Other studies showed that firmness is unaffected by light conditions or the fruit position in a tree (Dussi et al., 2009). However, these studies have been focused on determining the final ripeness and quality of peach at harvest, but not in the determination of the speed ripening unless the sample is destructively analyzed. Thus, it is a technical challenge to determine the ripening rate of a peach when it is still growing on-tree. In this sense, the absorbance of the chlorophyll of the skin in an interesting alternative that has shown correlation to the flesh firmness (Shinya et al., 2013; Ziosi et al., 2008). Interesting approaches for determining softening in peach during postharvest have been proposed by Tijskens et al. (2007) and Lurie et al. (2013). On the contrary, other studies have assessed the flesh firmness instead of the softening rate, presenting wrongly equivalent both terms (Ullah et al., 2013). Knowing how peaches ripe on-tree is essential for planning the management practices of the orchard to increase crop uniformity, improve fruit quality, and increase profitability. The hypothesis of this research was that peach fruit in the canopy follow the same pattern of ripening regardless of its location in the canopy. The objectives of this study were to characterize the evolution of the softening rate of the flesh and some physiological parameters of the fruit during the last phase on-tree.
Plant material. This study was conducted during two consecutive seasons (2010-11 and 2011-12) in two orchards located in the VI Region $\left(34^{\circ} 19^{\prime} 49.68^{\prime \prime} \mathrm{S} ; 70^{\circ} 50^{\prime} 1.88^{\prime \prime} \mathrm{W}\right)$ and the Metropolitan Region (33 $48^{\prime} 12.57^{\prime \prime} \mathrm{S}$; $\left.70^{\circ} 45^{\prime} 6.17^{\prime \prime} \mathrm{W}\right)$ in Chile. The plant material corresponds to the nonmelting fleshed peach cultivars Andes Du-1, Loadel, and Bowen, all of them grafted onto 'Nemaguard' rootstock and trained in epsilon shape. The rows in the orchard were planted in a north-south orientation, and they were drip irrigated. Three trees per cultivar were used. Fruit from the upper section of the canopy (between 1.7 and $3.0 \mathrm{~m}$ in height) and from the lower section (between 0.5 and $1.7 \mathrm{~m}$ in height) were harvested and evaluated separately. The trees used in this trial showed an interception of $50 \%$ to $60 \%$ of the photosynthetic active radiation, thus this was the parameter used to homogenize the size of the tree, reducing the effect it has on the average weight of the fruit (Reginato et al., 2007). Regulating the final fruit load was performed manually through thinning the fruits when they reached 15 to $25 \mathrm{~mm}$ diameter and leaving them separated $10-15 \mathrm{~cm}$ from each other along the twig. Under these conditions, which are the ones used by the industry, fruit reached an average size of 140 to $230 \mathrm{~g}$, which it is within the range required by the canning industry.

Monitoring peach ripening. During the first season and after manual thinning, five fruit located on the upper section of the canopy and five fruit located on the lower section were labeled for nondestructive monitoring of their on-tree development. The equatorial diameter was measured with a digital caliper (Veto, Santiago, Chile), and the absorbance of chlorophyll $\left(I_{\mathrm{AD}}\right)$ was measured with a DA-meter (Sinteleia, Bologna, Italy) on both cheeks of the labeled fruit. Moreover, between the stone-hardening phase and the harvest of each measurement date, another 15 fruit showing similar diameters and $I_{\mathrm{AD}}$ as the labeled fruits were harvested from each section of the canopy and transferred to the laboratory. The following parameters were measured: 1) background color of the skin, 2) SSC, 3) flesh firmness, 4) equatorial diameter ( $\mathrm{mm}), 5$ ) fruit mass $(\mathrm{g})$, and 6) $I_{\mathrm{AD}}$ of the skin. The background color was measured with a CR-400 Minolta portable colorimeter (Minolta, Tokyo, Japan) with illuminant D65 and an observer angle of $0^{\circ}$ using the CIELab system calibrated with a white standard. The SSC was ascertained with a thermo-compensated refractometer (Atago, Tokyo, Japan). The flesh firmness (N) was determined with an FTA GS-14 texture analyzer (Guss, Strand, South Africa) on each cheek before the removal of the skin, using a 7.9-mm-diameter probe with a penetration distance of $10 \mathrm{~mm}$ at a speed of $5 \mathrm{~mm} \cdot \mathrm{s}^{-1}$. Similarly, during the second season, measurements were made on 10 selected fruit from each section of the tree twice a week, beginning 5 weeks before the estimated harvest. The harvest was conducted when the 
background color changed from yellow-green to yellow and when the firmness of the flesh was between 36 and $44 \mathrm{~N}$.

Data analysis. To examine the evolution of $I_{\mathrm{AD}}$, a segmented linear regression model was used to describe the relationship by season, determining the time in which the $I_{\mathrm{AD}}$ displayed a linear decrease before harvest. This point, $\approx 10$ to $15 \mathrm{~d}$ before harvest, was considered the initial point of the phase of rapid softening. A completely randomized design was used, and the experimental unit was the whole tree. The comparisons between the cultivars and the sections of the canopy were performed with simple linear regression models under the framework of a mixed linear model. Treatments (cultivar and section), days after full bloom, and their joint interaction were considered as fixed effects. The seasons, trees, and fruit were considered random effects. The Akaike information criterion (Akaike, 1974) and Bayesian information criterion (Schwarz, 1978) were used to determine the goodness of fit of the selected model. The base temperature used for calculating the growing degree hours (GDH) was $10{ }^{\circ} \mathrm{C}$.

To determine differences between the lower and upper sections of the canopy, we conducted contrast testing on the regression slopes at the beginning of the phase of rapid maturation $(\alpha=0.05)$. Comparisons were made for each cultivar. The mixed model was fitted using the lme function of the nlme library of R software, version 2.15.2 (R Core Team, 2012) and the InfoStat statistical program, version 2013 (National University of Córdoba, Córdoba, Argentina).

\section{Results}

The $I_{\mathrm{AD}}$ showed a very slow evolution until the critical moment for each genotype, when there was a rapid degradation of chlorophyll (Fig. 1). This response followed a segmented, nonlinear regression. Beyond the intersection point of the two segments of the regression, the $I_{\mathrm{AD}}$ decreased linearly at a higher rate 10 to $15 \mathrm{~d}$ before harvest (Table 1). The most dramatic change in the $I_{\mathrm{AD}}$ progression coincided with the "color break," i.e., the rapid change in the background color of the skin from green to light yellow. Thus, the common point of both segments of the regression was also the break that marked the beginning of the change in skin color. In general, fruit ripening proceeded more rapidly during the 2011-12 season (Table 1) due to higher GDH accumulated after full bloom $30 \mathrm{~d}$ after full bloom (GDH30) that was registered during that season. Maturation was described based on the breakdown of the skin color, as given by the common point of both segments of the regression for a given season and cultivar (Fig. 1).

By integrating both seasons and the three cultivars using linear mixed models, we determined that the rates of change of both $I_{\mathrm{AD}}$ and flesh firmness through the time (softening) were similar in 'Andes Du-1' and 'Loadel'.
Additionally, in 'Bowen' and 'Loadel', there was no difference in their growth rate, as assessed by fruit diameter, mass, and the

evolution of the hue $\left(\mathrm{h}^{\circ}\right)$ component of the skin (Table 2). The cultivar-specific models for the fruit that grew at the lower and upper
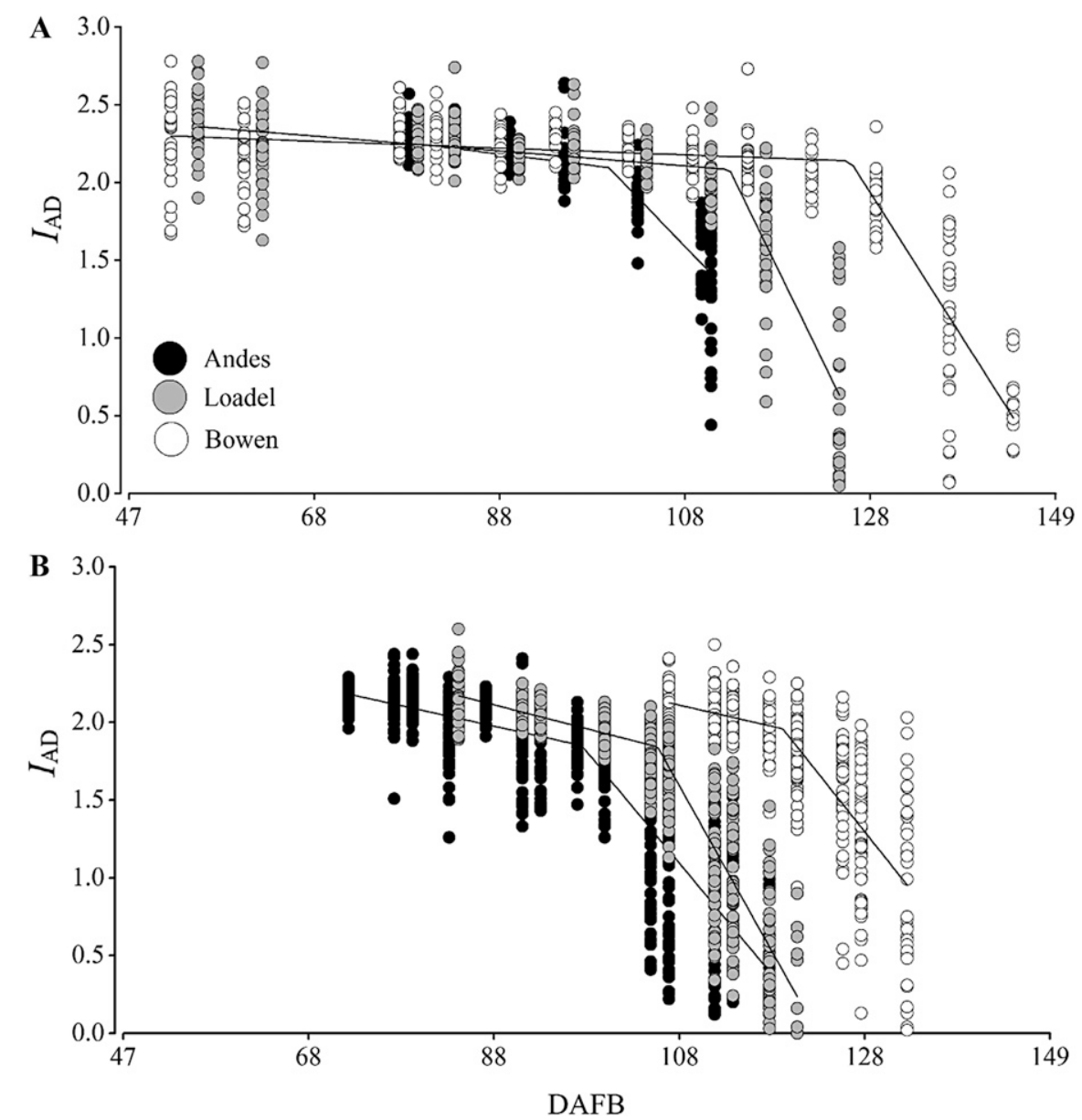

Fig. 1. Adjusted model for describing the evolution of the chlorophyll absorbance of the skin (IAD) as a function of the number of days after full bloom (DAFB) in three peach cultivars during 2010-11 (A) and 2011-12 (B) seasons in the Chilean central valley $(\mathrm{n}=15)$.

Table 1. Duration of the period of fruit growth till harvest (36- $44 \mathrm{~N}$ flesh firmness) of three peach cultivars, during two consecutive seasons in the Chilean central valley. The period is described according to the number of days after full bloom (DAFB) and the growing degree hours, base $10{ }^{\circ} \mathrm{C}$, which were accumulated $30 \mathrm{~d}$ after full bloom (DAFB30).

\begin{tabular}{lcccc}
\hline Cultivar & Full bloom (date) & $\begin{array}{c}\text { Color breakdown } \\
\text { (DAFB) }\end{array}$ & $\begin{array}{c}\text { Length of fruit } \\
\text { development period (DAFB) }\end{array}$ & GDH30 \\
\hline Andes Du-1 & 9 Sept. 2010 & 100 & 110 & 5,835 \\
Loadel & 13 Sept. 2011 & 97 & 105 & 6,355 \\
& 8 Sept. 2010 & 113 & 125 & 4,941 \\
Bowen & 13 Sept. 2011 & 106 & 121 & 5,688 \\
& 10 Sept. 2010 & 126 & 137 & 4,979 \\
& 13 Sept. 2011 & 119 & 133 & 5,688 \\
\hline
\end{tabular}

${ }^{\mathrm{z}}$ Common point for the two segments of the segmented linear regression.

Table 2. Values of the rates of change calculated between the "color break" of the skin and harvest (36-44 $\mathrm{N}$ flesh firmness) of different parameters associated with ripening. The parameters are the absorbance of the chlorophyll $\left(I_{\mathrm{AD}}\right)$ and the color of the skin, the fruit mass, the fruit diameter, the soluble solids content, and firmness of the flesh of three peach cultivars, during two consecutive seasons in the Chilean central valley.

\begin{tabular}{lccccccc}
\hline & \multicolumn{7}{c}{ Rate of change during ripening per day } \\
\cline { 2 - 8 } Cultivar & $I_{\mathrm{AD}}$ & Diam $(\mathrm{mm})$ & Mass $(\mathrm{g})$ & $\mathrm{C}^{*}$ & $\mathrm{~h}^{\circ}$ & $\mathrm{SSC}(\%)$ & Firmness (N) \\
\hline Andes Du-1 & $-0.08 \mathrm{~b}$ & $0.55 \mathrm{~b}$ & $3.95 \mathrm{~b}$ & $0.00 \mathrm{c}$ & $-2.35 \mathrm{a}$ & $0.00 \mathrm{~b}$ & $-2.41 \mathrm{~b}$ \\
Loadel & $-0.11 \mathrm{a}$ & $0.71 \mathrm{a}$ & $5.89 \mathrm{a}$ & $0.44 \mathrm{~b}$ & $-1.68 \mathrm{~b}$ & $0.01 \mathrm{a}$ & $-2.41 \mathrm{~b}$ \\
Bowen & $-0.08 \mathrm{~b}$ & $0.68 \mathrm{a}$ & $5.52 \mathrm{a}$ & $0.78 \mathrm{a}$ & $-1.88 \mathrm{~b}$ & $0.00 \mathrm{~b}$ & $-3.10 \mathrm{a}$ \\
\hline
\end{tabular}

Different letters indicate significant differences according to contrasts test $(P<0.05)$. 
Table 3. Differences in the rate of change of fruit quality parameters and the values of skin color break and harvest time between fruits growing in the bottom and upper sections of the canopy in nonmelting peach cultivars.

\begin{tabular}{|c|c|c|c|c|}
\hline \multirow[b]{2}{*}{ Traits } & \multirow[b]{2}{*}{ Cultivar } & \multicolumn{3}{|c|}{ Difference between sections } \\
\hline & & Skin color break & Harvest & Rate of change per day \\
\hline \multirow[t]{3}{*}{$\overline{I_{\mathrm{AD}}}$} & Andes Du-1 & $0.05^{\mathrm{NS}}$ & $0.41^{* *}$ & $0.02 *$ \\
\hline & Loadel & $0.09 *$ & $0.59 * * *$ & $0.03 * * *$ \\
\hline & Bowen & $0.12 *$ & $0.44 * * *$ & $0.02 * *$ \\
\hline \multirow{3}{*}{ Diameter $(\mathrm{mm})$} & Andes Du-1 & $-6.1 * * *$ & $-6.1 * * *$ & $0.0^{\mathrm{Ns}}$ \\
\hline & Loadel & $-1.4^{\mathrm{Ns}}$ & $-5.8 * * *$ & $-0.2^{* * *}$ \\
\hline & Bowen & $-6.4 * * *$ & $-7.0 * * *$ & $-0.0^{\mathrm{vs}}$ \\
\hline \multirow[t]{3}{*}{ Mass $(\mathrm{g})$} & Andes Du-1 & $-38.3 * * *$ & $-38.3 * * *$ & $0.0^{\mathrm{Ns}}$ \\
\hline & Loadel & $-8.9^{\mathrm{Ns}}$ & $-32.2 * * *$ & $1.3 * * *$ \\
\hline & Bowen & $-36.3 * * *$ & $-52.0 * * *$ & $1.0^{*}$ \\
\hline \multirow[t]{3}{*}{ Chroma $\left(\mathrm{C}^{*}\right)$} & Andes Du-1 & $-2.6 * * *$ & $-2.6^{* * *}$ & $0.00^{\mathrm{NS}}$ \\
\hline & Loadel & $-1.2^{\mathrm{Ns}}$ & $-2.4 *$ & $-0.07^{\mathrm{Ns}}$ \\
\hline & Bowen & $-1.9^{\mathrm{NS}}$ & $-2.2^{\mathrm{Ns}}$ & $-0.02^{\mathrm{Ns}}$ \\
\hline \multirow[t]{3}{*}{ Hue $\left(h^{\circ}\right)$} & Andes Du-1 & $3.4 * *$ & $3.4^{* *}$ & $0.00^{\mathrm{NS}}$ \\
\hline & Loadel & $-3.6^{\mathrm{NS}}$ & $7.6^{* * *}$ & $0.62 * * *$ \\
\hline & Bowen & $3.3 * *$ & $3.7^{* *}$ & $0.03 * *$ \\
\hline \multirow[t]{3}{*}{$\mathrm{SSC}(\%)$} & Andes Du-1 & $-1.5^{* * *}$ & $-1.5 * * *$ & $0.0^{\mathrm{Ns}}$ \\
\hline & Loadel & $-0.3^{\mathrm{Ns}}$ & $-2.2 * * *$ & $0.1 * * *$ \\
\hline & Bowen & $-0.9 * * *$ & $-0.9 * * *$ & $0.0^{\mathrm{Ns}}$ \\
\hline \multirow[t]{3}{*}{ Firmness $(\mathrm{N})$} & Andes Du-1 & $4.6^{* * *}$ & $4.6^{* * *}$ & $0.0^{\mathrm{Ns}}$ \\
\hline & Loadel & $1.6^{\mathrm{NS}}$ & $1.6^{\mathrm{NS}}$ & $0.0^{\mathrm{Ns}}$ \\
\hline & Bowen & $4.9^{\mathrm{Ns}}$ & $2.1^{\mathrm{Ns}}$ & $-0.2^{\mathrm{Ns}}$ \\
\hline
\end{tabular}

NS, ${ }^{*}, * *, * * *$ Nonsignificant or significant at $P \leq 0.05,0.01$, and 0.001 , respectively.

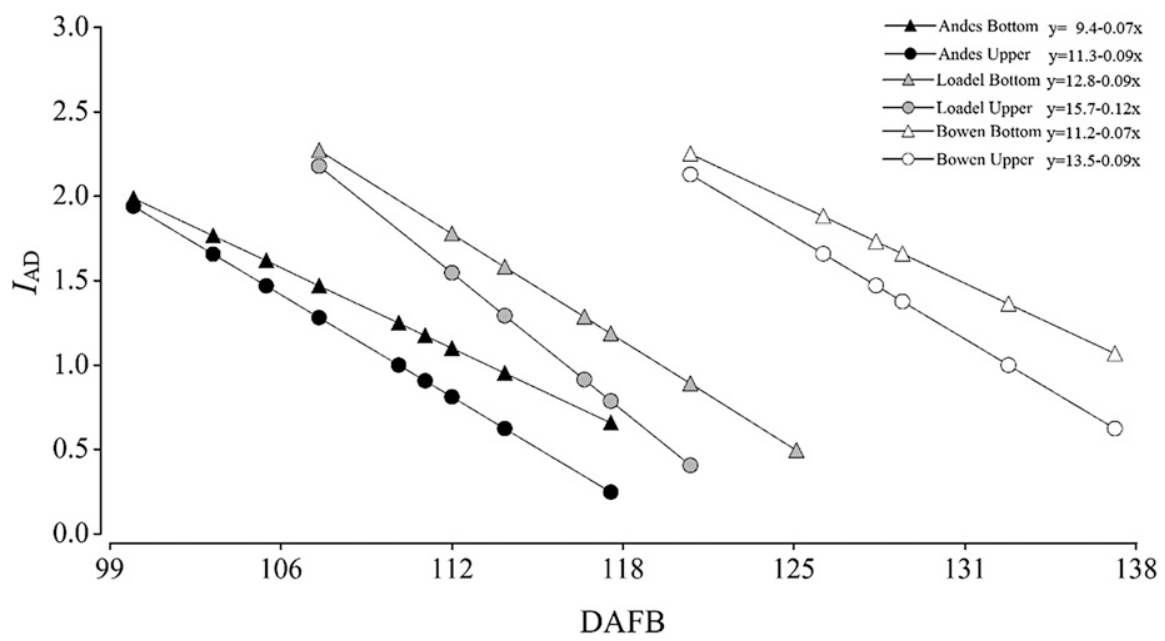

Fig. 2. Adjusted model for describing the evolution of chlorophyll absorbance of the skin (IAD) in peach cultivars located in bottom and upper sections of the canopy $(n=15)$.

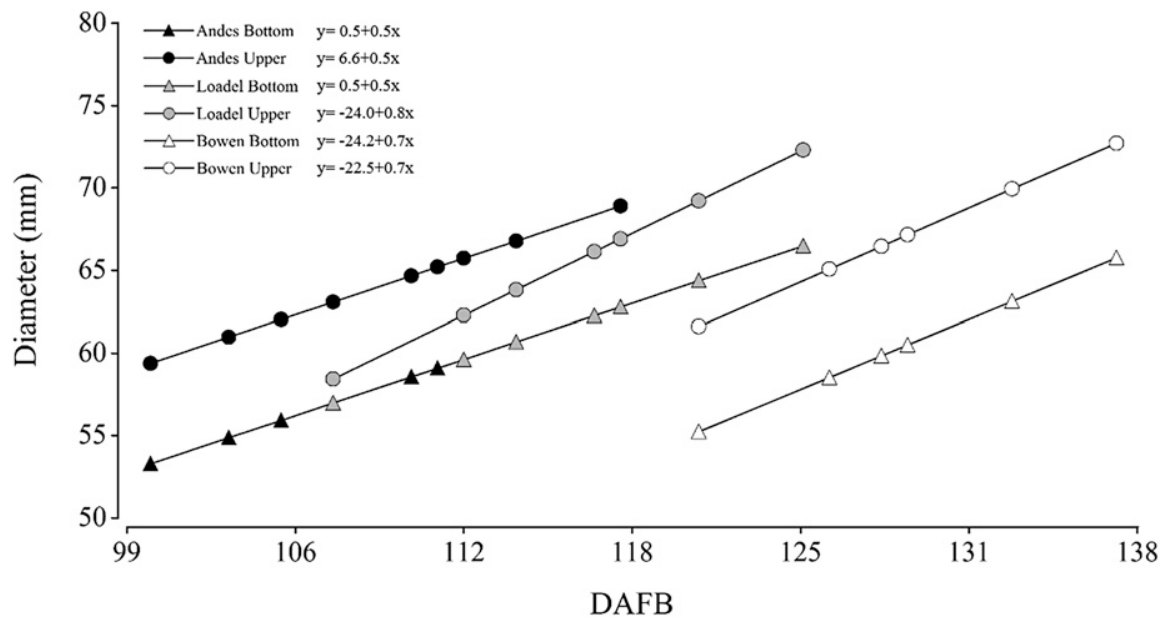

Fig. 3. Adjusted model for describing the evolution of the equatorial diameter $(\mathrm{mm})$ in three peach cultivars located in the bottom and upper sections of the canopy $(n=15)$. sections of the canopy reflect the difference in the rates of the change of the skin "color break" and the harvest between both sections. The rates of change and the value of $I_{\mathrm{AD}}$ reached at harvest differed between the two sections (Table 3). The fruit from the upper section of the canopy showed a higher rate of $I_{\mathrm{AD}}$ change (Fig. 2), with differences in $I_{\mathrm{AD}}$ at harvest ranging from 0.41 to 0.59 units among the fruit of each section (Table 3 ). Fruit growth was linear over the final 2 weeks of phase III (Fig. 3). The genotypes 'Andes Du-1' and 'Bowen' showed the same growth rate in both sections of the canopy. The difference of uneven ripeness levels can only be attributed to the fruit at the upper section reached before the "color break" (Fig. 3). In contrast, 'Loadel' showed different growth rates in the fruit from both sections of the canopy, which are reflected as different slopes (Table 3). However, for the three cultivars, the diameter of the fruit from the upper section of the canopy was larger than that of the fruit from the lower section at the time of harvest.

The fruit mass was estimated through the assessment of the equatorial diameter of the fruit, which showed an $r=0.98$ between both variables. It was observed that the fruit from the upper section of the canopy showed a mass of 30 to $50 \mathrm{~g}$ higher than the fruit from the lower section (Table 3 ). Furthermore, significant differences in the mass gain of 'Loadel' and 'Bowen' were observed, but this was not the case with 'Andes Du-1' (Fig. 4). In general, fruit from the lower section of the canopy showed higher chroma $\left(\mathrm{C}^{*}\right)$ values of the skin (Fig. 5). However, the rates of change of the $\mathrm{C}^{*}$ values were unaffected by the position of the fruit on the canopy (Table 3). In 'Andes Du-1', the $C^{*}$ value did not increase during the last phase on-tree, although differences were detected between both upper and lower sections. 'Loadel' differed only at the time of harvest, while no difference was observed between the two sections with the 'Bowen' fruit.

The $\mathrm{h}^{\circ}$ of the skin showed different rates of change between both sections on 'Loadel' and 'Bowen', with a greater decrease in the fruit from the upper section of the canopy (Fig. 5). In contrast, no such difference was observed on 'Andes Du-1'. In all the cultivars tested, fruit from the upper section showed lower $h^{\circ}$ values, closer to an orange color (Table 3). No significant changes in the evolution of the SSC were observed except with fruit of 'Loadel' located at the upper section of the canopy (Fig. 6), which increased during ripening. In general, the fruit from the upper section showed $1 \%$ to $2 \%$ higher SSC (Table 3) at harvest than the fruit from the lower section. In 'Loadel' and 'Bowen', no differences of flesh firmness were observed between the two sections (Table 3). However, 'Andes Du-1' fruit located at the upper section softened before the fruit at the lower section, although both sections presented the same softening rate (Fig. 7). 


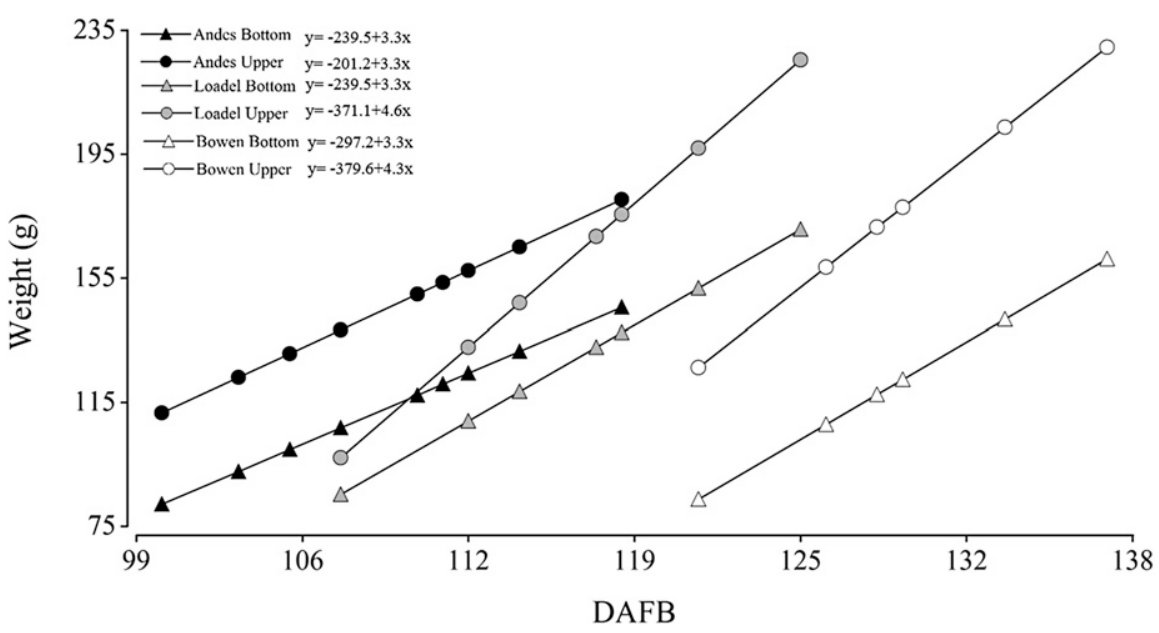

Fig. 4. Adjusted model for describing the evolution of the mass of the fruit $(\mathrm{g})$ in three peach cultivars located in the bottom and upper sections of the canopy. Values of fruit mass were estimated from the measured equatorial diameter of fruits in the field $(n=15)$.
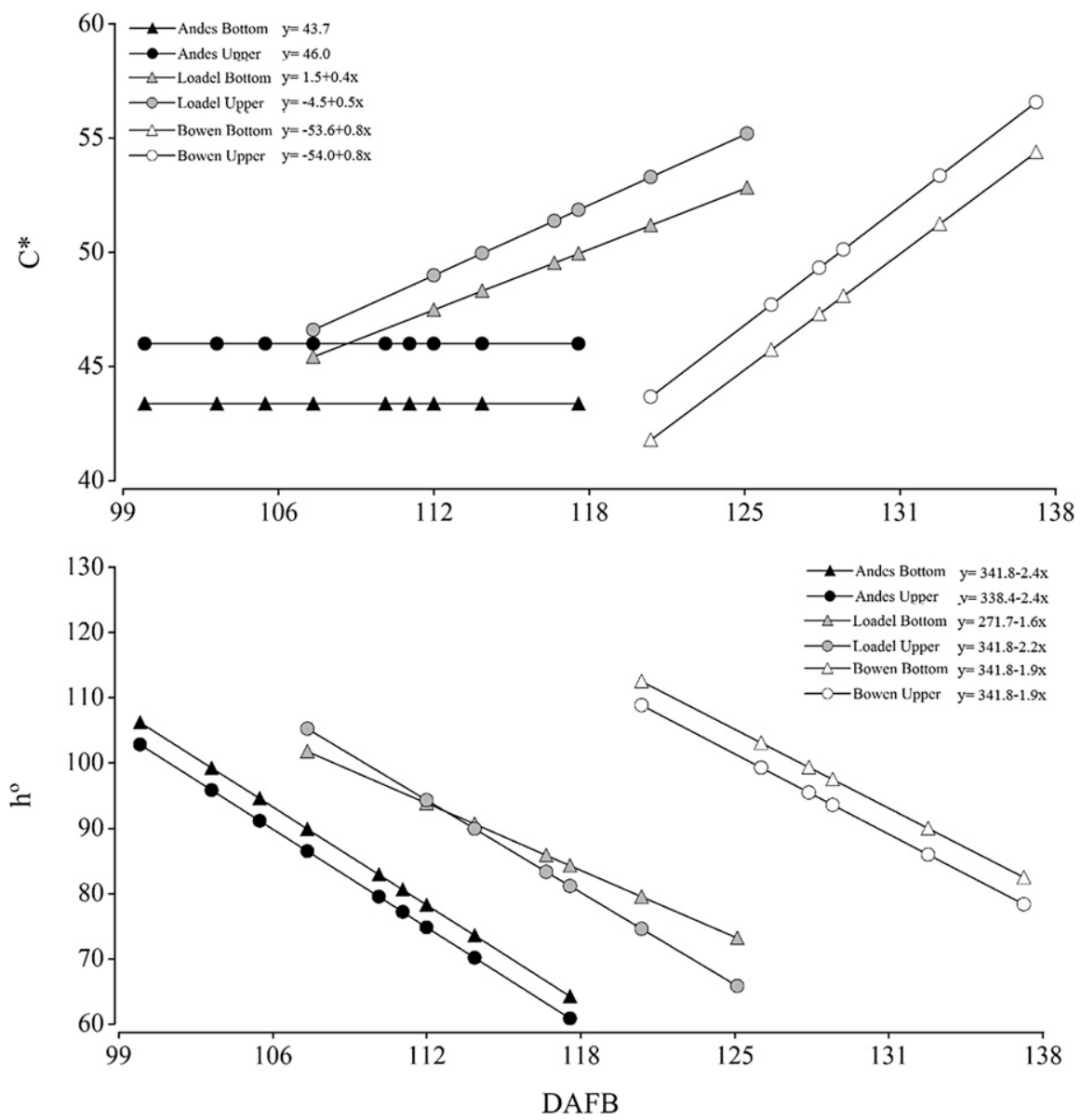

Fig. 5. Adjusted model for describing the evolution of the background color of the skin in terms of chroma $\left(\mathrm{C}^{*}\right)$ and the hue $\left(\mathrm{h}^{\circ}\right)$ in three peach cultivars located in the bottom and upper sections of the canopy $(\mathrm{n}=15)$.

\section{Discussion}

The change in background color occurred $\approx$ 2 weeks before harvest. This point showed an abrupt "color break," changing from green to light yellow, due to the loss of chlorophyll and the exposure of the carotenoids of the skin
(Giovannoni, 2004). As the degradation of chlorophyll is strongly correlated with maturation (Crisosto et al., 2007), it was appropriate to use the $I_{\mathrm{AD}}$ of chlorophyll to determine ripening. $I_{\mathrm{AD}}$ is strongly correlated with ethylene production and ripening of peach (Lurie et al., 2013; Shinya et al., 2013; Ziosi et al.,
2008). In addition, $I_{\mathrm{AD}}$ has a distinctive trend on nectarine showing an initial "plateau," and then a subsequent linear decrease until harvest (Bonora, 2013). The $I_{\mathrm{AD}}$ of the skin evolves in a similar way to that of the $h^{\circ}$ of the skin (data not shown). As the DA-meter is a portable device, it allows the assessment of fruit ontree. The "color break" was determined by fitting a segmented, nonlinear regression function, showing to be a simple way to characterize this biological process. The color change of the skin in peach is a critical phenotypic event, as the ground color is the primary criterion for harvesting peach in commercial orchards (Alcobendas et al., 2012). The span that goes from the "color break" of the skin to the moment of harvest shows a linear trend, and its slope is affected by the registered temperature of the growing season. As indicated by DeJong (2006), the differences in the length of the fruit development periods, evaluated during two consecutive seasons, are strongly influenced by the accumulated temperature after bloom. In this experiment, a higher GDH30 in the 2011-12 season determined more rapid ripening and, therefore, an earlier harvest.

Regarding growth and ripening, the effect of the fruit position on the canopy is a consequence of the variability of the age of each fruit (Tijskens et al., 2007). The first flowers that appear are primarily in the upper and outer parts of the canopy (Corelli-Grappadelli and Coston, 1991). Therefore, the fruit located in the upper section of the canopy begin to develop before the fruit located in the lower section, and these differences can be accentuated during the course of the season due to the higher temperatures of the end of the spring and summer. Larger fruits were observed at the upper sections at the time of harvest, as has also been reported by Caruso et al. (2001). Several authors have suggested that this difference is attributed to uneven light exposure, which would allow for superior production and a better supply of assimilates to the fruit located at the top of the canopy (Dussi et al., 2009; Farina et al., 2005; Luchsinger et al., 2002). Moreover, transpiration would be affected as well, as the most exposed fruit would have higher rates of transpiration, and consequently, a greater flow of both water and assimilates to enhance the dry matter content and SSC (Morandi et al., 2010). However, the growth rate did not differ between the two sections for 'Andes Du-1', although differences were observed before the "color break" on 'Andes Du-1' and 'Bowen'. According to Marini et al. (1991), light exposure would be the most influential factor in the middle of phase III of fruit growth, although the rate of growth for individual fruit is also sensitive to early shading.

Light exposure could explain a portion of the difference resulting from the position of the fruit on the canopy, as it determines the supply of assimilates for fruit development, although other factors accentuate these differences as well (Basile et al., 2007; Iacona et al., 2006). Specifically, the critical period of assimilates shortage begins 3 to 4 weeks 


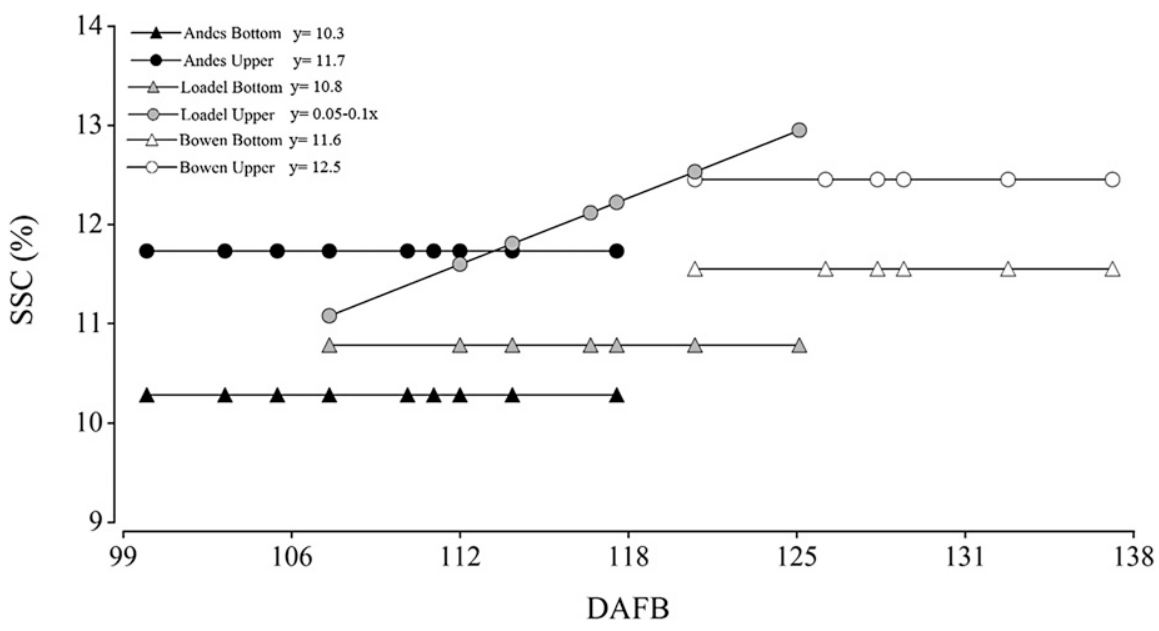

Fig. 6. Adjusted model for describing the evolution of the soluble solids concentration (\%) in three peach cultivars located in the bottom and upper sections of the canopy $(n=15)$.

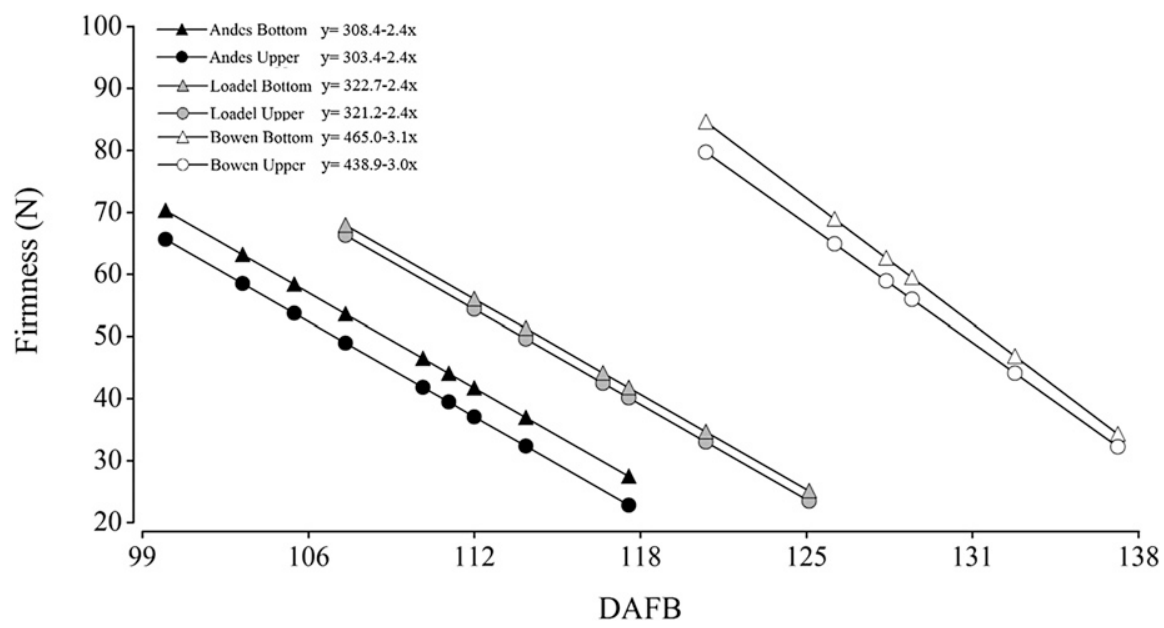

Fig. 7. Adjusted model for describing the evolution of the flesh firmness $(\mathrm{N})$ in three peach cultivars located in the bottom and upper sections of the canopy $(n=15)$.

after full bloom and extends until the harvest on early-maturing cultivars, such as with Andes Du-1. This critical period could be expressed in phases I and III on midseason cultivars, such as with Loadel and Bowen (Grossman and DeJong, 1995). The effect of this limitation would be amplified in peach due to the reduced availability of assimilates as a consequence of the high crop load (Basile et al., 2007; Costa and Vizzotto, 2000). Moreover, particularly with 'Andes Du-1' and 'Bowen', which showed a high initial load, a strong limiting condition exists for the growth of the fruit during phase I (Ojer et al., 2001). These limiting conditions are critical for fruit located at the lower section of a canopy. In contrast, 'Loadel' presents a lower initial crop load (Ojer et al., 2011), and thus competition for products of photosynthesis for growth between the shoots and the fruitlets is not as relevant in this case (Basile et al., 2007).

The SSC was significantly higher in the fruit at the upper section of the canopy, which confirms previous reports (Lewallen and Marini, 2003; Luchsinger et al., 2002).
The conditions for obtaining assimilates are better at this part of the canopy. The SSC remained constant in the last 2 weeks of phase III growth in 'Andes Du-1' and 'Bowen'. In contrast, 'Loadel' showed an increase in SSC due to the increased availability of assimilates. The results for $I_{\mathrm{AD}}$ reflect the tendency of the fruit at the upper section to lose chlorophyll from the skin more rapidly than those at the lower section. Additionally, the evolution of the background color of the skin showed that the fruit in the upper section expressed a more vivid color (higher $\mathrm{C}^{*}$ ) at harvest, as described by Alcobendas et al. (2012). It is important to underline that the loss of chlorophyll and the synthesis of pigments during maturation are not interdependent events. The total degradation of chlorophyll is required to allow the color to be expressed in pure form and with a more satisfactory tone (Seymour et al., 1993). Therefore, the fruit from the lower section of the canopy had higher $I_{\mathrm{AD}}$ and lower carotenoid content at harvest when compared with the more exposed fruit (Ferrer et al., 2005).
The firmness of the flesh showed no difference between the two sections of the canopy in 'Loadel' and 'Bowen', as previously reported (Alcobendas et al., 2012; Dussi et al., 2009). However, differences were found between both sections in "Andes Du-1'; at the "color break," the firmness of the flesh was lower in the fruit located at the upper section, and remained so until harvest (Remorini et al., 2006). There was no difference in the softening rate of the fruit from both sections of the canopy, but fruit from the upper section began to soften earlier, which was an effect that was marked in 'Andes Du-1'. According to Eccher Zerbini et al. (2006), some difference in flesh firmness is explained by the different ages of the individual fruit (i.e., the time from flowering to harvest), as young fruit reach the rapid softening phase later than those formed earlier. This observation explains why shaded fruit may be delayed by $\approx 7$ days in reaching commercial maturity in comparison with more exposed fruit (Bonora, 2013), as well as why no direct relationship is found regarding light conditions (Lewallen and Marini, 2003). Other studies have confirmed that softening rates follow the same pattern in all fruit, and that variations are determined by the degree of maturity of each individual fruit (Eccher Zerbini et al., 2006; Tijskens et al., 2007). These findings indicate that the softening rate has a strong genetic component in comparison with the other parameters of peach maturity. Consequently, when ripeness monitoring starts at the time of the "color break," flesh firmness is a reliable indicator for predicting the onset of the harvest time in advance.

\section{Conclusions}

The ripeness level of the peach from the upper section of the canopy is more advanced than the fruit from the lower section, but the peach flesh softening rate is unaffected by the location of the fruit on the canopy. The differences in fruit size, SSC, $I_{\mathrm{AD}}$, and background color depend on the position of where the fruit are located on the canopy throughout the growing season. The mixed modeling of peach ripening allowed for a correct and efficient analysis of observation, based on repeated sampling over time. This approach will be useful to describe the evolution of peach ripening and the programing of harvest, after confirming its goodness of fit under different conditions.

\section{Literature Cited}

Akaike, H. 1974. A new look at the statistical model identification. IEEE Trans. Automat. Contr. 19:716-723.

Alcobendas, R., J.M. Mirás-avalos, J.J. Alarcón, F. Pedrero, and E. Nicolás. 2012. Combined effects of irrigation, crop load and fruit position on size, color and firmness of fruits in an extraearly cultivar of peach. Sci. Hort. 142:128-135.

Basile, B., L.I. Solari, and T.M. DeJong. 2007. Intra-canopy variability of fruit growth rate in peach trees grafted on rootstocks with different 
vigour-control capacity. J. Hort. Sci. Biotechnol. 82:243-256.

Bonora, E. 2013. Modeling systems and vis/NIR device to improve peach and nectarine pre and post-harvest fruit maturity management. Doctorate in Arboreal Crops and Ornamental Agrosystems Forestry and Landscape. University of Bologna, Italy.

Caruso, T., P. Inglese, C. Di Vaio, and L.S. Pace. 2001. Effect of different fruit-thinning patterns on crop efficiency and fruit quality for greenhouse-forced "May Glo" nectarine trees. HortTechnology 11:412-415.

Corelli-Grappadelli, L. and D.C. Coston. 1991. Thinning pattern and light environment in peach tree canopies influence fruit quality. HortScience 26:1464-1466.

Costa, G. and G. Vizzotto. 2000. Fruit thinning of peach trees. Plant Growth Regulat. 31:113-119.

Crisosto, C.H., R.S. Johnson, T. Dejong, and K.R. Day. 1997. Orchard factors affecting postharvest stone fruit quality. HortScience 32:820-823.

Crisosto, C.H., F.G. Mitchell, and S. Johnson. 1995. Review article: Factors in fresh market stone fruit quality. Postharvest News Inf. 6:17-21.

Crisosto, C.H., C. Valero, and D.C. Slaughter. 2007. Predicting pitting damage during processing in californian clingstone peaches using color and firmness measurements. Appl. Eng. Agr. 23:1-6.

DeJong, T.M. 2006. Physiological and developmental principles of peach tree and fruit growth related to management practices. Acta Hort. 713:161-168.

Dussi, M.C., G. Giardina, G. Giménez, P. Reeb, K. Zon, and J. Nyeki. 2009. Influence of light interception on vegetative and productive development of peaches cv. Elegant Lady. Rev. FCA UNCuyo 41:155-164.

Eccher Zerbini, P., M. Vanoli, M. Grassi, A. Rizzolo, M. Fibiani, R. Cubeddu, A. Pifferi, L. Spinelli, and A. Torricelli. 2006. A model for the softening of nectarines based on sorting fruit at harvest by time-resolved reflectance spectroscopy. Postharvest Biol. Technol. 39: 223-232.

Farina, V., R. Lo Bianco, and P. Inglese. 2005. Vertical distribution of crop load and fruit quality within vase- and $\mathrm{Y}$-shaped canopies of "Elegant Lady" peach. HortScience 40: 587-591.

Ferrer, A., S. Remo, A.I. Negueruela, and R. Oria. 2005. Changes during the ripening of the very late season Spanish peach cultivar Calanda feasibility of using CIELAB coordinates as maturity indices. Sci. Hort. 105:435-446.

Forlani, M., B. Basile, C. Cirillo, and C. Iannini. 2002. Effects of harvest date and fruit position along the tree canopy on peach fruit quality. Acta Hort. 592:459-466.

George, A., S. Hieke, T. Rasmussen, and P. Lüdders. 1996. Early shading reduces fruit yield and late shading reduces quality in low-chill peach in subtropical Australia. J. Hort. Sci. Biotechnol. 71:561-571.

Giovannoni, J. 2004. Genetic regulation of fruit development and ripening. Plant Cell 16: 170-180.

Grossman, Y.L. and T.M. DeJong. 1995. Maximum fruit growth potential and seasonal patterns of resource dynamics during peach growth. Ann. Bot. (Lond.) 75:553-560.

Iacona, C., M. Bernardini, F. Loreti, and R. Muleo. 2006. Solar radiation affects "Stark Redgold" nectarine fruit growth and development. Acta Hort. 713:209-215.

Lewallen, K. 2000. Effects of light availability and canopy position on peach fruit quality. Master of Science in Horticulture. Faculty of the Virginia Polytechnic Institute and State University, Blacksburg, VA.

Lewallen, K.S. and R.P. Marini. 2003. Relationship between flesh firmness and ground color in peach as influenced by light and canopy position. J. Amer. Soc. Hort. Sci. 128:163-170.

Luchsinger, L., P. Ortin, G. Reginato, and R. Infante. 2002. Influence of canopy fruit position on the maturity and quality of "Angelus" peaches. Acta Hort. 592:515-521.

Lurie, S., H. Friedman, A. Weksler, A. Dagar, and P. Eccher Zerbini. 2013. Maturity assessment at harvest and prediction of softening in an early and late season melting peach. Postharvest Biol. Technol. 76:10-16.

Marini, R.P., D. Sowers, and M.C. Marini. 1991. Peach fruit quality is affected by shade during final swell of fruit growth. J. Amer. Soc. Hort. Sci. 116:383-389.
Morandi, B., L. Manfrini, P. Losciale, M. Zibordi, and L. Corelli-Grappadelli. 2010. The positive effect of skin transpiration in peach fruit growth. J. Plant Physiol. 167:1033-1037.

Ojer, M., F. Vallejos, and G. Reginato. 2011. Variedades, p. 31-42. In: M. Ojer (ed.). Producción de duraznos para industria. FCA, Universidad Nacional de Cuyo, Mendoza.

Ojer, M., C. Arjona, and G. Reginato. 2001. Incidencia de la carga inicial de frutos sobre la producción y la calidad de frutos en duraznero cv. Bowen. Invest. Agr. Prod. Prot. Veg. 16:25-35.

R Core Team. 2012. R: A language and environment for statistical computing. R Foundation for Statistical Computing, Vienna, Austria. 21 June 2013. <http://www.R-project.org/>.

Reginato, G., V. García de Cortazar, and T. Robinson. 2007. Predicted crop value for nectarines and cling peaches of different harvest season as a function of crop load. HortScience 42:239-245.

Remorini, D., F. Loreti, and R. Massai. 2006. Determination of maturity stage and fruit quality in peach by skin's optical properties. Acta Hort. 713:471-476.

Schwarz, G. 1978. Estimating the dimension of a model. Ann. Stat. 6:461-464.

Seymour, G., J. Taylor, and G. Tucker. 1993. Biochemistry of fruit ripening. Chapman and Hall, London, UK.

Shinya, P., L. Contador, S. Predieri, P. Rubio, and R. Infante. 2013. Peach ripening: Segregation at harvest and postharvest flesh softening. Postharvest Biol. Technol. 86:472-478.

Tijskens, L.M.M., P. Eccher Zerbini, R.E. Schouten, M. Vanoli, S. Jacob, M. Grassi, R. Cubeddu, L. Spinelli, and A. Torricelli. 2007. Assessing harvest maturity in nectarines. Postharvest Biol. Technol. 45:204-213.

Ullah, S., A. Sattar Khan, A. Ullah Malik, and M. Shahid. 2013. Cultivar and harvest location influence fruit softening and antioxidative activities of peach during ripening. Intl. J. Agr. Biol. 15:1059-1066.

Ziosi, V., M. Noferini, G. Fiori, A. Tadiello, L. Trainotti, G. Casadoro, and G. Costa. 2008. A new index based on vis spectroscopy to characterize the progression of ripening in peach fruit. Postharvest Biol. Technol. 49:319-329. 